\title{
EMERGÊNCIA DO CAPIM-MARMELADA EM DUAS REGIÕES DO ESTADO DO PARANÁ ${ }^{1}$
}

\author{
BENEDITO NOEDI RODRIGUES ${ }^{2}$, ELEMAR VOLL ${ }^{3}$, INÊS FUMIKO UBUKATA YADA ${ }^{4}$ e JOÃO DE LIMA ${ }^{5}$
}

\begin{abstract}
RESUMO - O objetivo do trabalho foi determinar a periodicidade e intensidade da emergência, bem como a sobrevivência de sementes de capim-marmelada (Brachiaria plantaginea (Link) Hitch.) em duas regiões do Estado do Paraná. O delineamento experimental foi o de blocos ao acaso, no esquema fatorial $2 \times 3 \times 2$, com três repetições. Os fatores estudados foram: tempo de permanência e profundidade de distribuição das sementes no solo, e manejo do solo. Foram utilizados cilindros de cerâmica instalados em condições de campo, numa rotação trigo/soja. Os cilindros receberam solo esterilizado, até os limites estabelecidos para a profundidade de distribuição das sementes. Nessas profundidades foram colocadas telas de plástico, sobre as quais foram acrescentados volumes complementares de solo contendo 300 sementes de B. plantaginea. A cada 14 dias, a partir da instalação do experimento, foram feitas contagens e arrancadas as plântulas emergidas nos cilindros. As sementes recuperadas dos cilindros foram submetidas a testes de germinação em laboratório. Os maiores picos de emergência ocorreram no verão, coincidindo com as elevações da temperatura e precipitação pluvial. Houve maior emergência no tratamento com revolvimento do solo. As maiores emergências ocorreram quando as sementes estavam em profundidades menores. A germinação das sementes que permaneceram no solo por um ano foi mais intensa do que a das que permaneceram por dois anos.
\end{abstract}

Termos para indexação: Brachiaria plantaginea, ervas daninhas, sementes, solo, germinação, dinâmica de populações.

\section{EMERGENCE OF BRACHIARIA PLANTAGINEA (LINK) HITCH. IN TWO REGIONS OF PARANÁ STATE, BRAZIL}

\begin{abstract}
The objective of this experiment was to determine the periodicity and intensity of emergence as well as the survival of Brachiaria plantaginea (Link) Hitch. seeds in two regions of Paraná State, Brazil. A randomized complete block in factorial design $2 \times 3 \times 2$, with three replications was used. The factors studied were: seed survival in the soil; seed burial depth, and soil management. Ceramic cylinders were installed in a wheat/soybean rotation under field conditions. The cylinders were filled with sterilized soil up to the limits established for the depth of seed distribution. A plastic net was placed into the cylinders to separate the treated soil from the untreated soil used to fill the cylinders. Three hundred seeds of $B$. plantaginea were mixed to the untreated soil. The weed seedlings were counted every 14 days and pulled out of the cylinders. The highest peak of $B$. plantaginea emergence occurred in the summer, coincidently with the period of highest temperature and rainfall. There was more emergence in tilled than in no-tilled soil. The highest emergences occurred in the smallest depth. The germination percentage of the seeds removed from the cylinders was higher in one year than two-year buried seeds.
\end{abstract}

Index terms: Brachiaria plantaginea, weed, seed, soil, germination, population dynamics.

\footnotetext{
${ }^{1}$ Aceito para publicação em 28 de março de 2000.

${ }^{2}$ Eng. Agrôn., Ph.D., Instituto Agronômico do Paraná (IAPAR), Caixa Postal 481, CEP 86001-970 Londrina, PR. E-mail: noedi@pr.gov.br

${ }^{3}$ Eng. Agrôn., Ph.D., Embrapa-Centro Nacional de Pesquisa de Soja (CNPSo), Caixa Postal 231, CEP 86001-970 Londrina, PR. E-mail: voll@cnpso.embrapa.br

${ }^{4}$ Eng. Agrôn., M.Sc., IAPAR. E-mail: inesyada@pr.gov.br

${ }^{5}$ Eng. Químico, M.Sc., IAPAR. E-mail: jolima@pr.gov.br
}

\section{INTRODUÇÃO}

Em estudos de dinâmica de populações de plantas daninhas, é necessário conhecer o banco de sementes do solo, a biologia das espécies que o compõem, e os efeitos das práticas de manejo sobre elas.

Debaeke \& Sebilotte (1988) observaram que a composição qualitativa e quantitativa da flora dani- 
nha de um local reflete o sistema de cultivo em uso. Fernandez-Quintanilla (1988) cita que para ter um valor de predição, é necessário relacionar o comportamento das espécies daninhas do solo com as várias práticas de manejo executadas e os principais processos fisiológicos e ecológicos envolvidos.

Sabe-se que apenas parte das sementes germina no solo. Segundo Barralis \& Chadoeuf (1980), apenas $6,6 \%$ do banco de sementes emergiu durante o ciclo da cevada. Stoller \& Wax (1973) observaram que a distribuição e a intensidade da emergência de várias espécies de plantas daninhas relacionaram-se primariamente com a ocorrência de chuvas.

Yenish et al. (1992) verificaram que a concentração de sementes no solo decresce de forma logarítmica em plantio direto, com o aumento da profundidade, enquanto no plantio convencional a distribuição é uniforme em todas as camadas do solo. Roberts \& Feast (1973) observaram um decréscimo exponencial do número de sementes viáveis de ano para ano, em média de $32 \%$, em solo cultivado, e de $12 \%$ em solo não cultivado, incluindo todas as espécies. As populações declinaram mais rapidamente (duas a três vezes) em solos cultivados do que em solos não cultivados. A emergência de plântulas foi reduzida em até $19 \%$, com um cultivo. Em solo cultivado, cerca da metade $(50 \%)$ resultou em plântulas no período de seis anos, ao passo que apenas $20 \%$, em solo não movimentado, e destes, quase a metade emergiu no primeiro ano.

Vários fatores contribuem para a persistência de sementes de plantas daninhas no solo; por exemplo, alta longevidade, germinação ao mesmo tempo que a cultura, dormência, não-germinação a grandes profundidades, e elevada produção de sementes. West \& Marousky (1989) observaram que o envelhecimento das sementes aumenta sua germinação. Altas temperaturas aumentam os processos fisiológicos, aumentando também a germinação (Shaffer \& Chilcote 1970; West \& Marousky, 1989). Estação do ano, localização no perfil (Dawson \& Burns,1975; Schwertzel, 1976; Thomas, 1977; Egley \& Chandler, 1978; Leguizamón, 1986) e cultivo do solo (Roberts \& Feast, 1972, 1973; Schwertzel \& Thomas, 1979; Pollard et al., 1982) também interferem no processo de dormência das sementes. Voll et al. (1995), estudando o capim-marmelada (Brachiaria plantaginea
(Link) Hitch.) no campo, verificaram que a sobrevivência dessa espécie foi menor em solos movimentados do que nos não movimentados.

O objetivo deste experimento foi determinar a periodicidade e a intensidade da emergência, bem como a sobrevivência das sementes de $B$. plantaginea em duas regiões do Estado do Paraná.

\section{MATERIAL E MÉTODOS}

O experimento foi conduzido nas Estações Experimentais do Instituto Agronômico do Paraná-IAPAR, nos municípios de Londrina e Ponta Grossa, respectivamente. $\mathrm{O}$ delineamento experimental adotado foi o de blocos ao acaso, no esquema fatorial $2 \times 3 \times 2$, com três repetições. Os fatores estudados foram: tempo $(\mathrm{T})$ de permanência das sementes no solo (1 e 2 anos); profundidade $(\mathrm{P})$ de distribuição das sementes no solo $(0-4 \mathrm{~cm} ; 0-8 \mathrm{~cm}$; 0-20 cm) e revolvimento (R) do solo (com e sem).

Foram utilizados cilindros de cerâmica de $20 \mathrm{~cm}$ de diâmetro interno por $30 \mathrm{~cm}$ de comprimento, instalados no campo, numa rotação trigo/soja. Os cilindros foram enterrados verticalmente, deixando-se uma borda livre de $3,0 \mathrm{~cm}$ acima do nível do solo, para proteção interna, dispostos em espaçamento de $40 \mathrm{~cm}$ (entre fileiras) por $40 \mathrm{~cm}$ (dentro das fileiras), medido pelas bordas dos cilindros.

$\mathrm{O}$ solo utilizado para encher os cilindros foi peneirado em malha de $2,0 \mathrm{~mm}$ e tratado com brometo de metila, para a eliminação das sementes de plantas daninhas indesejáveis. O tratamento foi feito sob cobertura impermeável, durante dois dias, e depois a cobertura foi removida, $\mathrm{e}$, por igual período, feito o arejamento do solo.

Os cilindros receberam solo tratado até os limites estabelecidos para profundidade de enterramento das sementes. Nessas profundidades foram colocadas telas de plástico de malhas de $0,5 \mathrm{~mm}$, sobre as quais foram acrescentados os volumes complementares de solo contendo 300 sementes de B. plantaginea por cilindro, uniformemente misturadas. As telas tiveram a finalidade de evitar a perda de sementes para profundidades maiores, quando das operações de revolvimento do solo. As telas não foram fixadas nos cilindros. As sementes da planta daninha utilizada neste estudo foram recém-colhidas na própria região de cada experimento, em área próxima ao experimento de cada local.

A semeadura das culturas trigo/soja foi feita manualmente, em sulcos marcados entre as fileiras dos cilindros previamente enterrados no solo.

O trigo foi semeado em maio/junho de cada ano (1994 e 1995), em espaçamento de $20 \mathrm{~cm}$. Nas duas linhas definidas pela parede externa de cada fileira de cilindros, a 
$2 \mathrm{~cm}$ delas abriram-se sulcos no terreno, sendo dois sulcos entre cada fileira de cilindros. $\mathrm{O}$ adubo recomendado pela análise do solo foi colocado no fundo do sulco, e misturado levemente com a terra, para que não entrasse em contato direto com as sementes. Em seguida, as sementes de trigo foram depositadas nos sulcos e cobertas com terra.

A semeadura da soja foi realizada em outubro/novembro de cada ano (1994 e 1995), em sulcos abertos entre as fileiras de cilindros (um sulco entre cada fileira), ao espaçamento de $60 \mathrm{~cm}$. O adubo recomendado para a soja foi colocado no fundo do sulco, misturando-o levemente com a terra. Em seguida, as sementes foram depositadas nos sulcos e cobertas com terra.

As cultivares de trigo e soja, densidades de semeadura, adubação e tratos culturais necessários a essas culturas, foram os recomendados pela pesquisa oficial do Estado do Paraná. As colheitas do trigo e da soja foram realizadas manualmente, cortando-se as hastes a $7 \mathrm{~cm}$ do solo.

No tratamento com revolvimento do solo, a operação foi feita logo após a colheita do trigo e logo após a colheita da soja, correspondendo às épocas comuns de preparo do solo na lavoura. A porção de solo contendo as sementes remanescentes ou não-germinadas, situada acima das telas divisórias, foi retirada dos cilindros, colocada em sacos de plástico e revolvida uniformemente, por agitação manual, durante um minuto, e depois foi recolocada nos respectivos cilindros.

Para avaliar a periodicidade e a intensidade de emergência da espécie, a cada 14 dias a partir da instalação do experimento foram feitas contagens e arranquio das plântulas emergidas nos cilindros. Qualquer outra espécie de planta que emergiu nos cilindros foi também eliminada por arranquio manual.

Para avaliar a sobrevivência das sementes, por meio do fator "tempo de permanência das sementes no solo", toda a terra contendo as sementes remanescentes das plantas daninhas, situada acima das telas de plástico foi retirada, colocada em sacos de plástico com a devida identificação, e enviada ao laboratório para ser submetida ao processo de flotação, descrito a seguir. A retirada da terra de cada série de cilindros, correspondente ao tempo de permanência no solo, foi feita uma vez por ano, após a colheita da soja.

A porção do solo contendo as sementes retiradas dos cilindros, uma vez enviada ao laboratório, foi submetida a lavagem com água corrente, em peneiras de malha de $0,5 \mathrm{~mm}$. Após breve exposição das sementes e o resíduo remanescente de solo ao ar, para a evaporação da água, a amostra foi flotada num béquer, em solução saturada de $\mathrm{CaCl}_{2} \cdot \mathrm{H}_{2} \mathrm{O}$ (Roberts \& Ricketts, 1979), com densidade em torno de $1,42 \mathrm{~g} / \mathrm{mL}$, controlada com densímetro. As sementes flutuaram, permitindo a separação das partículas de solo, que decantaram. Uma vez recuperadas, essas sementes foram submetidas a teste de germinação.

O teste de germinação foi feito no Laboratório de Sementes do IAPAR, com método especial para esta finalidade.

Os dados de precipitação pluvial e temperatura média nos dois anos de condução do experimento são apresentados na Fig. 1 (junho de 1994 a maio de 1996).

Os resultados experimentais foram submetidos à análise da variância, e as médias, à comparação pelo teste de Tukey a $5 \%$ de probabilidade.

\section{RESULTADOS E DISCUSSÃO}

Após dois anos de estudo, tanto em Londrina (Fig. 2) como em Ponta Grossa (Fig. 3) verificou-se que os picos de emergência ocorreram no verão, coincidindo com as maiores precipitações pluviais desses locais (Fig. 1). Stoller \& Wax (1973) obtiveram resultados semelhantes com a utilização de várias espécies de plantas daninhas.

No primeiro ano, em solo com revolvimento, as porcentagens de plântulas emergidas em Londrina e Ponta Grossa foram semelhantes (Tabela 1). No entanto, as porcentagens de sementes recuperadas foram maiores em Londrina do que em Ponta Grossa. Resultado semelhante foi observado no solo não-revolvido. Em ambos os locais, as porcentagens de sementes recuperadas aumentaram com o aumento da profundidade de distribuição das sementes no solo. No segundo ano, a tendência dos valores foi semelhante à do primeiro ano. No tratamento com revolvimento do solo, a porcentagem de plântulas emergidas geralmente foi maior do que no tratamento sem revolvimento do solo, nos dois locais, o que coincide com os dados observados por Voll et al. (1995).

A interação entre o tempo de enterramento e a profundidade de distribuição das sementes no solo não foi significativa em relação ao número de plântulas emergidas em Londrina (Tabela 2). Em Ponta Grossa, houve redução no número de plântulas emergidas com o aumento da profundidade. O número de sementes recuperadas, em ambos os locais, foi significativamente menor na profundidade de 0-4 cm, e o número de sementes perdidas foi maior. Dados semelhantes foram obtidos por 
Roberts \& Feast (1972) e Leguizamón (1986). Esses autores observaram maior sobrevivência de espécies em maiores profundidades.

Houve maior germinação das sementes recuperadas após um ano do que após dois anos de enterramento das sementes tanto em Londrina, como em Ponta Grossa (Tabela 3). Nos dois anos houve maior germinação das sementes recuperadas da profundidade de 0-20 $\mathrm{cm}$. O número de plantas anormais nos dois locais, nos dois anos, foi menor na profundidade de 0-4 cm. Em Londrina, o número de sementes mortas foi maior após um ano do que após dois anos de enterramento, sendo maior nas profundidades maiores. Em Londrina, o número de sementes dormentes foi maior após dois anos de enterramento. Em Ponta Grossa não houve diferença significativa.

Trabalhos de Schwertzel (1976) citam que as espécies podem apresentar diferentes graus de sobre-
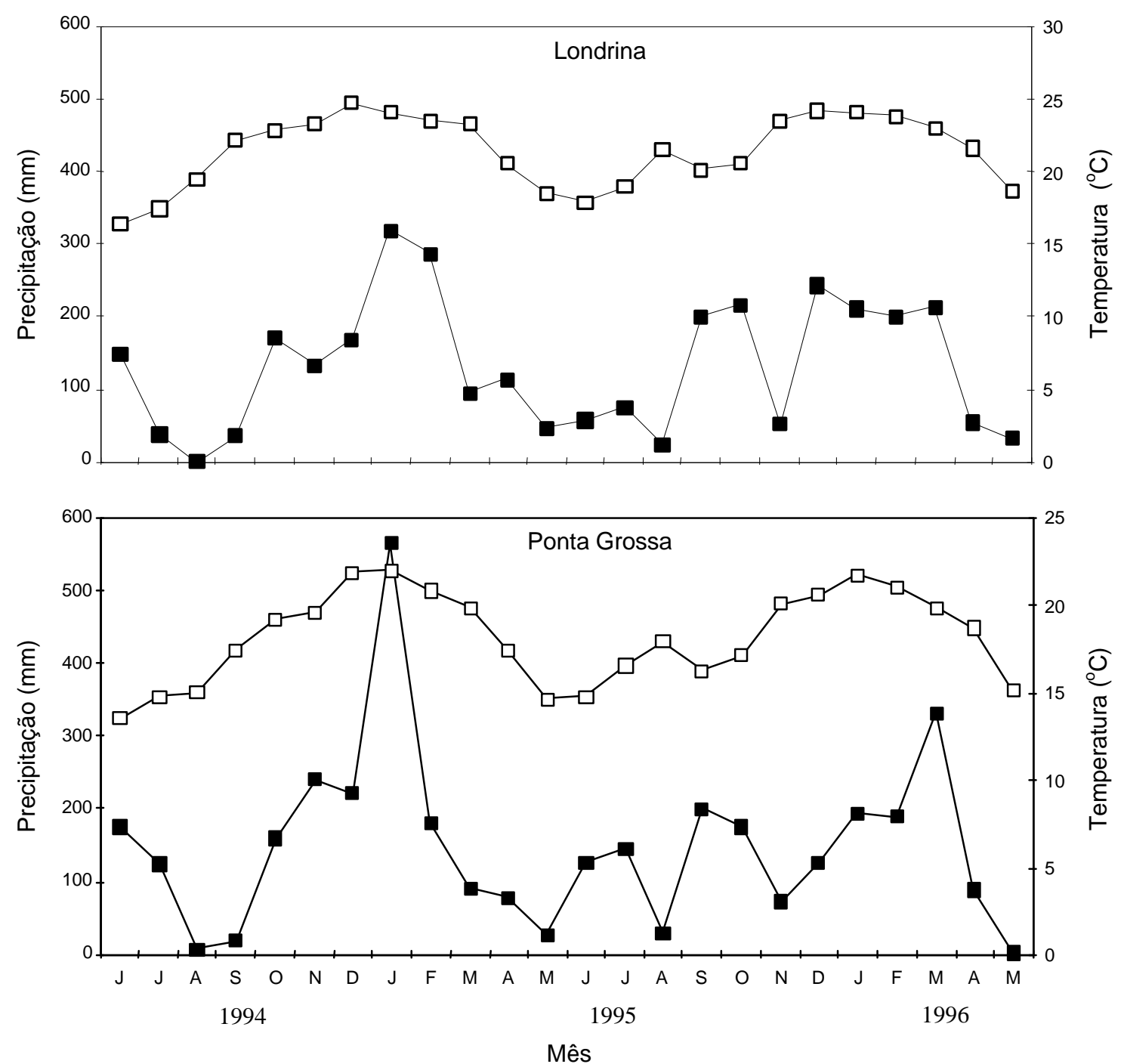

FIG. 1. Precipitação ( $\square$ ) e temperatura média ( $\square$ ) durante dois anos de duração do experimento, em Londrina e Ponta Grossa. 

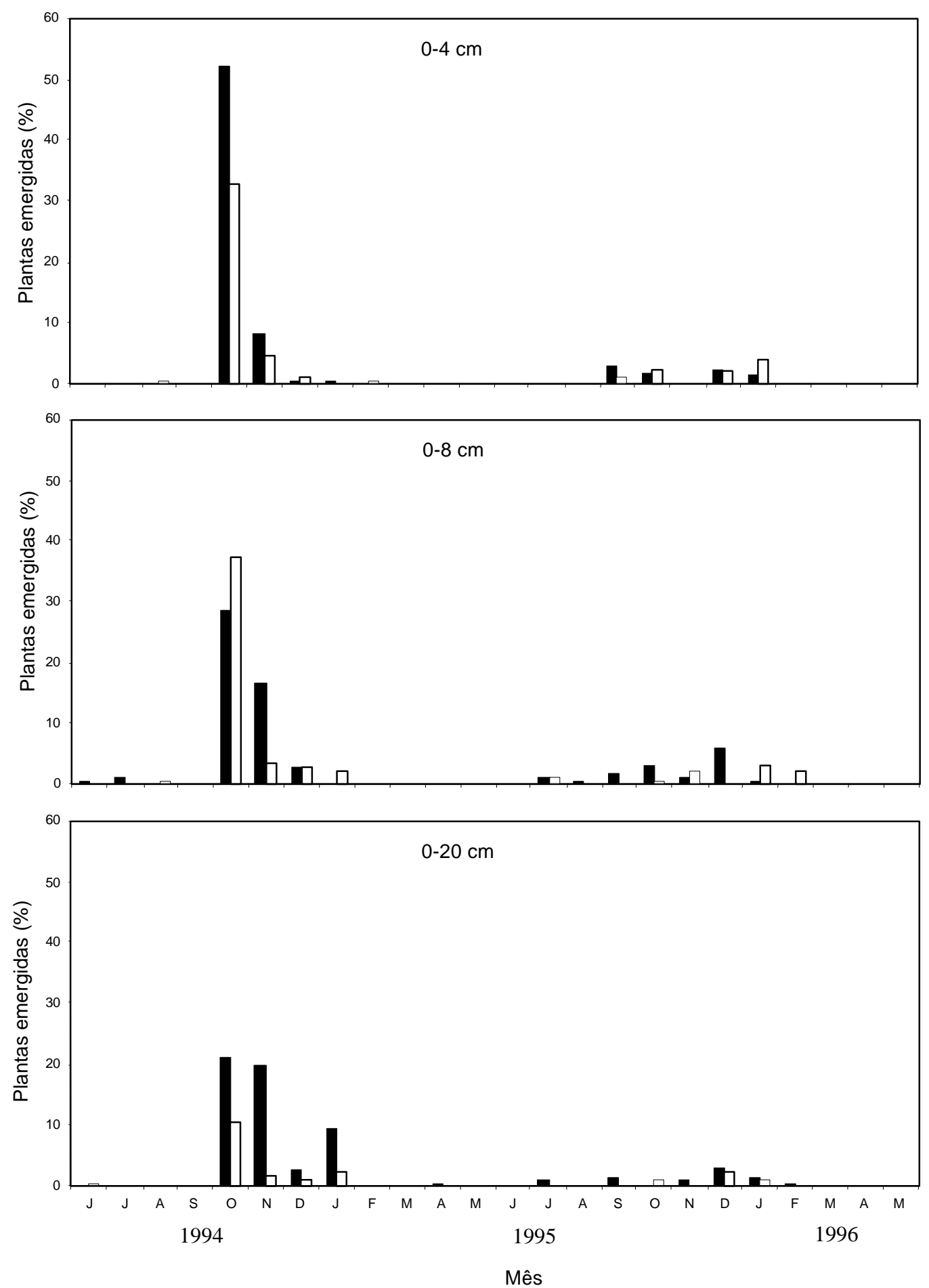

FIG. 2. Emergência de B. plantaginea em Londrina, com (ఐ) e sem ( $\square$ ) revolvimento do solo. 

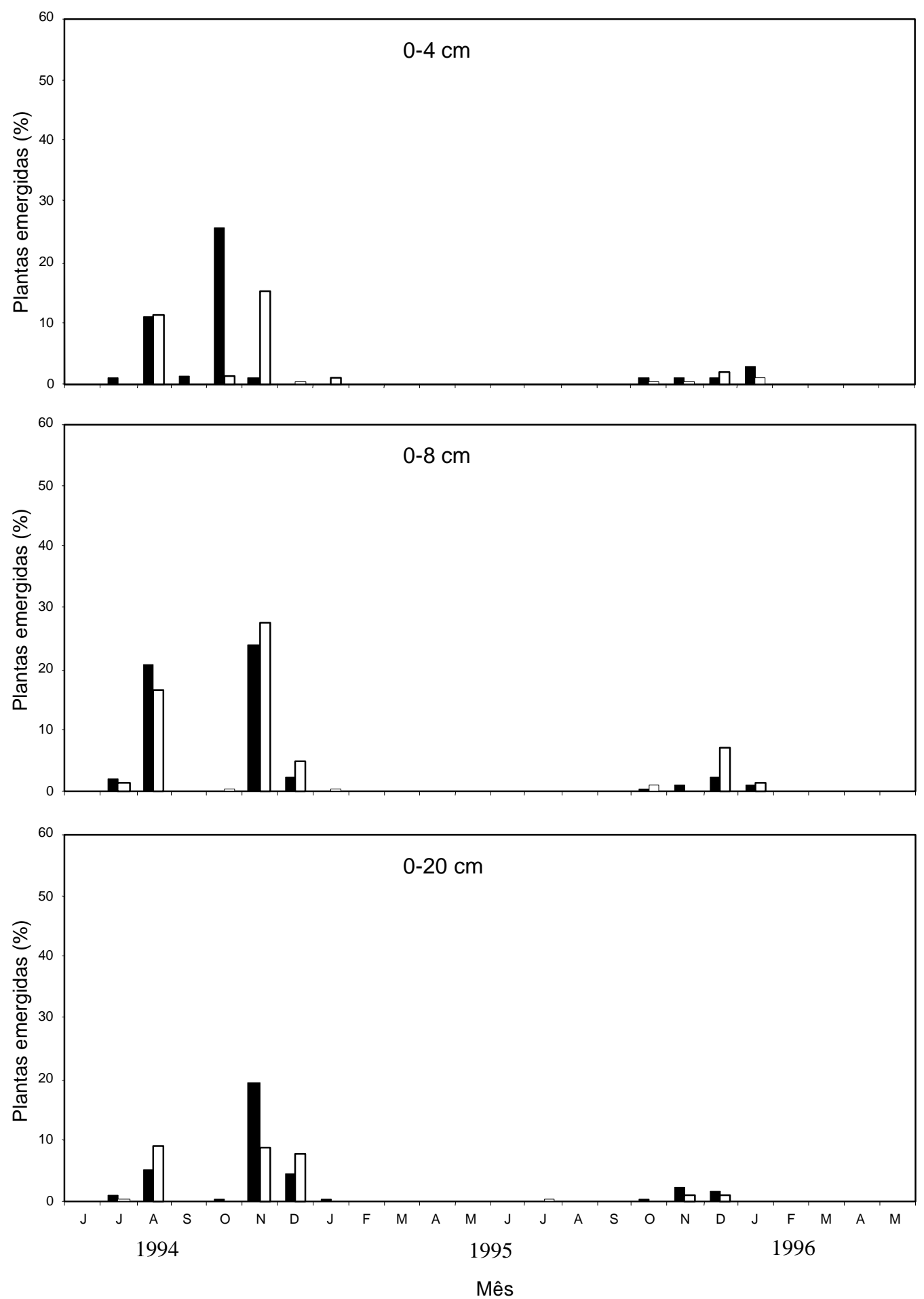

FIG. 3. Emergência de B. plantaginea em Ponta Grossa, com (घ) e sem ( $\square$ ) revolvimento do solo. 
TABELA 1. Porcentagem de sementes emergidas, recuperadas e perdidas, originárias de sementes de B. plantaginea em razão da permanência das mesmas por um e dois anos em solo revolvido (R) e não-revolvido (NR) e da profundidade (0-4, 0-8 e 0-20 cm) de distribuição no solo de Londrina (LD) e de Ponta Grossa (PG).

\begin{tabular}{|c|c|c|c|c|c|c|c|c|c|c|c|c|c|c|c|c|c|c|c|}
\hline \multirow[t]{3}{*}{ Ano } & \multirow{3}{*}{$\begin{array}{l}\text { Preparo } \\
\text { do solo }\end{array}$} & \multicolumn{6}{|c|}{ Emergidas } & \multicolumn{6}{|c|}{ Recuperadas } & \multicolumn{6}{|c|}{ Perdidas } \\
\hline & & \multicolumn{2}{|c|}{$0-4 \mathrm{~cm}$} & \multicolumn{2}{|c|}{$0-8 \mathrm{~cm}$} & \multicolumn{2}{|c|}{$0-20 \mathrm{~cm}$} & \multicolumn{2}{|c|}{$0-4 \mathrm{~cm}$} & \multicolumn{2}{|c|}{$0-8 \mathrm{~cm}$} & \multicolumn{2}{|c|}{$0-20 \mathrm{~cm}$} & \multicolumn{2}{|c|}{$0-4 \mathrm{~cm}$} & \multicolumn{2}{|c|}{$0-8 \mathrm{~cm}$} & \multicolumn{2}{|c|}{$0-20 \mathrm{~cm}$} \\
\hline & & LD & PG & $\mathrm{LD}$ & PG & LD & PG & LD & PG & LD & PG & LD & PG & $\mathrm{LD}$ & PG & LD & PG & LD & PG \\
\hline \multirow[t]{2}{*}{1} & $\mathrm{R}$ & 11 & 11 & 14 & 13 & 11 & 12 & 22 & 12 & 43 & 27 & 62 & 45 & 67 & 77 & 43 & 60 & 26 & 44 \\
\hline & NR & 15 & 15 & 13 & 17 & 5 & 9 & 30 & 16 & 55 & 32 & 82 & 33 & 55 & 69 & 33 & 51 & 12 & 58 \\
\hline \multirow[t]{2}{*}{2} & $\mathrm{R}$ & 23 & 14 & 21 & 18 & 21 & 12 & 13 & 5 & 32 & 10 & 34 & 17 & 64 & 81 & 47 & 72 & 46 & 71 \\
\hline & NR & 16 & 11 & 18 & 20 & 6 & 9 & 20 & 16 & 41 & 23 & 64 & 35 & 64 & 73 & 41 & 57 & 30 & 56 \\
\hline
\end{tabular}

TABELA 2. Efeito de permanência e da profundidade de distribuição das sementes no número de plântulas emergidas, número de sementes recuperadas e no número de sementes perdidas, em diferentes profundidades. Dados transformados em $\sqrt{\mathrm{x}+1}$. IAPAR, Londrina, PR1.

\begin{tabular}{|c|c|c|c|c|c|c|c|c|c|}
\hline \multirow{2}{*}{$\begin{array}{c}\text { Tempo } \\
\text { (ano) }\end{array}$} & \multicolumn{3}{|c|}{ Número de plântulas emergidas } & \multicolumn{3}{|c|}{ Número de sementes recuperadas } & \multicolumn{3}{|c|}{ Número de sementes perdidas } \\
\hline & $0-4 \mathrm{~cm}$ & $0-8 \mathrm{~cm}$ & $0-20 \mathrm{~cm}$ & $0-4 \mathrm{~cm}$ & $0-8 \mathrm{~cm}$ & $0-20 \mathrm{~cm}$ & $0-4 \mathrm{~cm}$ & $0-8 \mathrm{~cm}$ & $0-20 \mathrm{~cm}$ \\
\hline 1 & $6,1 \mathrm{Aa}$ & $6,3 \mathrm{Aa}$ & $5,0 \mathrm{Aa}$ & $8,5 \mathrm{Ab}$ & $12,0 \mathrm{Aa}$ & $14,7 \mathrm{Aa}$ & $13,4 \mathrm{Aa}$ & $10,5 \mathrm{Aa}$ & $7,4 \mathrm{Bb}$ \\
\hline \multirow[t]{2}{*}{2} & $7,5 \mathrm{Aa}$ & $7,6 \mathrm{Aa}$ & $6,1 \mathrm{Aa}$ & $6,9 \mathrm{Ab}$ & $10,5 \mathrm{Aa}$ & $12,0 \mathrm{Aa}$ & $13,8 \mathrm{Aa}$ & $11,5 \mathrm{Aab}$ & $10,6 \mathrm{Ab}$ \\
\hline & \multicolumn{9}{|c|}{ Ponta Grossa } \\
\hline 1 & $6,3 \mathrm{Aa}$ & $6,8 \mathrm{Aa}$ & $5,6 \mathrm{Ab}$ & $6,4 \mathrm{Ab}$ & $9,4 \mathrm{Aa}$ & $10,8 \mathrm{Aa}$ & $14,8 \mathrm{Aa}$ & $12,8 \mathrm{Ab}$ & $12,3 \mathrm{Ab}$ \\
\hline 2 & $6,2 \mathrm{Ab}$ & 7,6Aa & $5,7 \mathrm{Ab}$ & $5,4 \mathrm{Ab}$ & $6,9 \mathrm{Ba}$ & $8,5 \mathrm{Ba}$ & $15,2 \mathrm{Aa}$ & $13,9 \mathrm{Aa}$ & 13,7Aa \\
\hline
\end{tabular}

1 Médias seguidas da mesma letra, maiúscula na coluna e minúscula na linha, não diferem pelo teste de Tukey a $5 \%$ de probabilidade; os coeficientes de variação em relação ao número de plântulas emergidas, número de sementes recuperadas e número de sementes perdidas foram, respectivamente, de 20,2, 17,6 e 17,9\% em Londrina e de 10,8, 19,4 e 8,3\% em Ponta Grossa. 


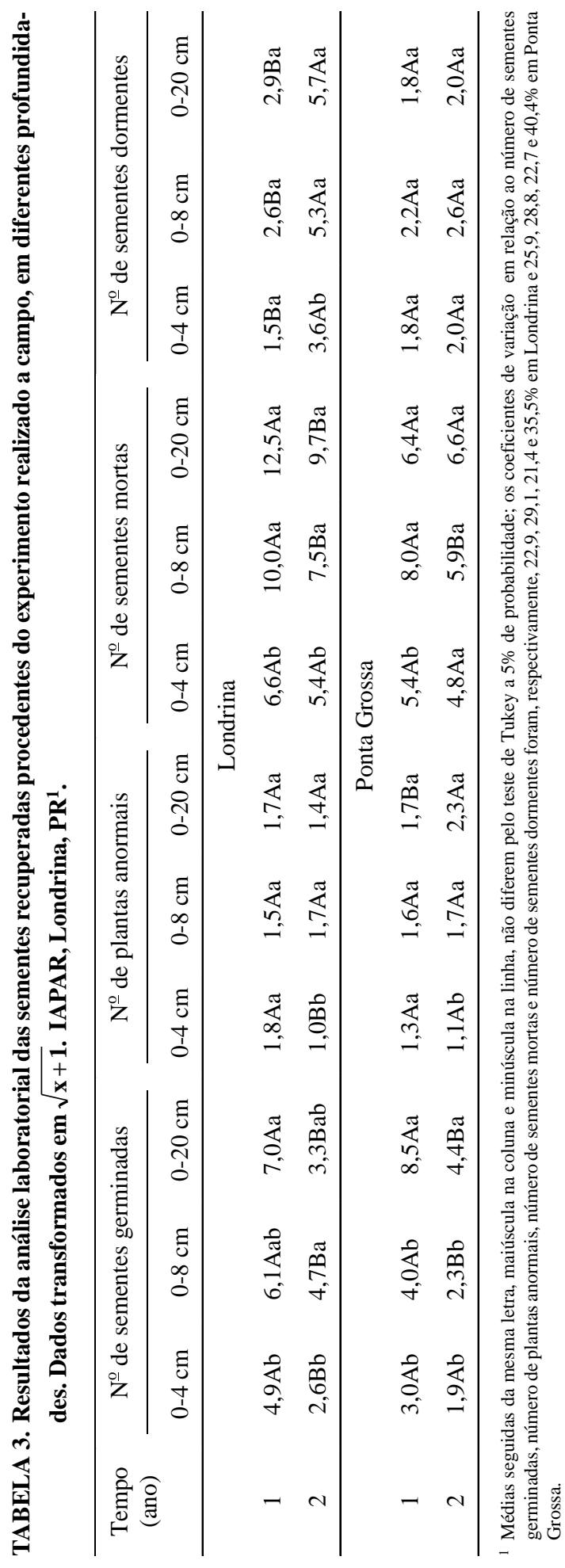

vivência no perfil do solo. Além disso, podem apresentar dormência rítmica nas camadas superiores, ou permanente, nas inferiores (Leguizamón, 1986), o que deve impedir tanto a germinação como a morte das sementes em profundidades maiores do solo.

Em Londrina, no solo revolvido, o número de plântulas emergidas foi maior após dois anos de enterramento o que já não ocorreu quando o solo não foi revolvido (Tabela 4). Em Ponta Grossa não houve efeito significativo da interação entre a permanência das sementes no solo e o revolvimento ou não do solo sobre o número de plântulas emergidas. Nos dois locais, após o primeiro ano, não houve diferença significativa entre o número de sementes recuperadas do solo revolvido e não-revolvido. Entretanto, nos dois locais, após o segundo ano, o número de sementes recuperadas do solo não-revolvido foi maior. Em números absolutos, houve menor número de sementes perdidas após um ano do que após dois anos de enterramento, em ambos os locais.

Houve maior germinação das sementes recuperadas após um ano de enterramento, tanto em solo revolvido como no não-revolvido. Não houve diferença entre o primeiro e o segundo ano em relação ao número de plantas anormais em Ponta Grossa. Em Londrina, tanto em solo revolvido como em nãorevolvido, o número de sementes mortas foi menor após o segundo ano de enterramento. Em Ponta Grossa, foi menor em solo revolvido, após o segundo ano de enterramento. Em Londrina, tanto em solos com revolvimento como sem revolvimento, o número de sementes dormentes foi maior após dois anos de enterramento. Em Ponta Grossa, entre o tempo de permanência das sementes no solo e o revolvimento ou não do solo, não houve efeito da interação sobre o número de sementes dormentes.

Resultados semelhantes a estes foram obtidos por Voll et al. (1995), que em trabalho de cinco anos observaram que a emergência de $B$. plantaginea em plantio convencional (com revolvimento do solo), foi maior do que em plantio direto (sem revolvimento do solo).

Em Londrina, nas profundidades menores, não houve efeito do revolvimento ou não do solo sobre o número de plântulas emergidas (Tabela 5). Em Ponta Grossa e em Londrina, o número de plantas emergidas em solos não-revolvidos foi menor na maior profun- 
TABELA 4. Efeito do tempo de permanência das sementes no solo em razão do revolvimento (R) e não-revolvimento (NR) do solo, no número de plântulas emergidas, número de sementes recuperadas, número de sementes perdidas, número de sementes germinadas, número de plantas anormais, número de sementes mortas e número de sementes dormentes. Dados transformados em $\sqrt{\mathrm{x}+1}$. IAPAR, Londrina, PR ${ }^{1}$.

\begin{tabular}{|c|c|c|c|c|c|c|c|c|c|c|c|c|c|c|}
\hline \multirow[t]{2}{*}{$\begin{array}{c}\text { Tempo } \\
\text { (ano) }\end{array}$} & \multicolumn{2}{|c|}{$\begin{array}{c}\text { № de plântulas } \\
\text { emergidas }\end{array}$} & \multicolumn{2}{|c|}{$\begin{array}{l}\text { № de sementes } \\
\text { recuperadas }\end{array}$} & \multicolumn{2}{|c|}{$\begin{array}{l}\text { № de sementes } \\
\text { perdidas }\end{array}$} & \multicolumn{2}{|c|}{$\begin{array}{l}\text { № de sementes } \\
\text { germinadas }\end{array}$} & \multicolumn{2}{|c|}{$\begin{array}{l}\text { № de plantas } \\
\text { anormais }\end{array}$} & \multicolumn{2}{|c|}{$\begin{array}{c}\text { № de sementes } \\
\text { mortas }\end{array}$} & \multicolumn{2}{|c|}{$\begin{array}{c}\text { № de sementes } \\
\text { dormentes }\end{array}$} \\
\hline & $\mathrm{R}$ & NR & $\mathrm{R}$ & NR & $\mathrm{R}$ & NR & $\mathrm{R}$ & NR & $\mathrm{R}$ & NR & $\mathrm{R}$ & NR & $\mathrm{R}$ & NR \\
\hline & \multicolumn{14}{|c|}{ Londrina } \\
\hline 1 & $5,9 \mathrm{Ba}$ & $5,7 \mathrm{Aa}$ & $10,8 \mathrm{Aa}$ & $12,6 \mathrm{Aa}$ & $11,3 \mathrm{Aa}$ & $9,5 \mathrm{Aa}$ & $5,4 \mathrm{Ab}$ & $6,6 \mathrm{Aa}$ & $1,6 \mathrm{Aa}$ & $1,6 \mathrm{Aa}$ & $9,0 \mathrm{Aa}$ & $10,3 \mathrm{Aa}$ & $2,2 \mathrm{Ba}$ & $2,5 \mathrm{Ba}$ \\
\hline \multirow[t]{2}{*}{2} & $8,0 \mathrm{Aa}$ & $6,1 \mathrm{Ab}$ & $8,7 \mathrm{Bb}$ & $10,8 \mathrm{Aa}$ & $12,5 \mathrm{Aa}$ & $11,4 \mathrm{Aa}$ & $3,1 \mathrm{Ba}$ & $4,0 \mathrm{Ba}$ & $1,4 \mathrm{Aa}$ & $1,3 \mathrm{Aa}$ & $6,8 \mathrm{Ba}$ & $8,3 \mathrm{Ba}$ & 4,4Aa & $5,3 \mathrm{Aa}$ \\
\hline & \multicolumn{14}{|c|}{ Ponta Grossa } \\
\hline 1 & $6,0 \mathrm{Aa}$ & $6,4 \mathrm{Aa}$ & 8,9Aa & $8,8 \mathrm{Aa}$ & $13,4 \mathrm{Ba}$ & $13,3 \mathrm{Aa}$ & $5,0 \mathrm{Aa}$ & $5,4 \mathrm{Aa}$ & $1,3 \mathrm{Aa}$ & $1,7 \mathrm{Aa}$ & $6,8 \mathrm{Aa}$ & $6,4 \mathrm{Aa}$ & $1,8 \mathrm{Aa}$ & $2,1 \mathrm{Aa}$ \\
\hline 2 & $6,6 \mathrm{Aa}$ & $6,3 \mathrm{Aa}$ & $5,5 \mathrm{Bb}$ & $8,4 \mathrm{Aa}$ & $15,0 \mathrm{Aa}$ & $13,6 \mathrm{Ab}$ & $2,4 \mathrm{Ba}$ & $3,3 \mathrm{Ba}$ & $1,5 \mathrm{Ab}$ & $2,0 \mathrm{Aa}$ & $4,6 \mathrm{Bb}$ & 7,0Aa & $1,9 \mathrm{Aa}$ & $2,5 \mathrm{Aa}$ \\
\hline
\end{tabular}

${ }^{1}$ Médias seguidas da mesma letra, maiúscula na coluna e minúscula na linha, não diferem pelo teste de Tukey a 5\% de probabilidade; os coefientes de variação em relação ao número de plântulas emergidas, número de sementes recuperadas, número de sementes perdidas, número de sementes germinadas, número de plantas anormais, número de sementes mortas e número de sementes dormentes foram, respectivamente, 20,2, 17,6, 17,9, 22,9, 29,1, 21,4 e 35,5\% em Londrina e 10,8, 19,4, 8,3, 25,9, 28,8, 22,7 e 40,4\% em Ponta Grossa.

TABELA 5. Efeito da profundidade (P) de distribuição da semente no solo em razão do revolvimento (R) e não-revolvimento (NR) do solo, no número de plântulas emergidas, número de sementes recuperadas, número de sementes perdidas, número de sementes germinadas, número de plantas anormais, número de sementes mortas e número de sementes dormentes. Dados transformados em $\sqrt{\mathrm{x}+1}$. IAPAR, Londrina, PR ${ }^{1}$.

\begin{tabular}{|c|c|c|c|c|c|c|c|c|c|c|c|c|c|c|}
\hline \multirow[t]{2}{*}{$\begin{array}{c}\mathrm{P} \\
(\mathrm{cm})\end{array}$} & \multicolumn{2}{|c|}{$\begin{array}{c}\text { № de plântulas } \\
\text { emergidas }\end{array}$} & \multicolumn{2}{|c|}{$\begin{array}{l}\mathrm{N}^{\mathrm{o}} \text { de sementes } \\
\text { recuperadas }\end{array}$} & \multicolumn{2}{|c|}{$\begin{array}{c}\text { № de sementes } \\
\text { perdidas }\end{array}$} & \multicolumn{2}{|c|}{$\begin{array}{c}\text { № de sementes } \\
\text { germinadas }\end{array}$} & \multicolumn{2}{|c|}{$\begin{array}{c}\mathrm{N}^{\mathrm{o}} \text { de plantas } \\
\text { anormais }\end{array}$} & \multicolumn{2}{|c|}{$\begin{array}{c}\mathrm{N}^{\mathrm{o}} \text { de sementes } \\
\text { mortas }\end{array}$} & \multicolumn{2}{|c|}{$\begin{array}{c}\mathrm{N}^{\mathrm{o}} \text { de sementes } \\
\text { dormentes }\end{array}$} \\
\hline & $\mathrm{R}$ & NR & $\mathrm{R}$ & NR & $\mathrm{R}$ & NR & $\mathrm{R}$ & NR & $\mathrm{R}$ & NR & $\mathrm{R}$ & NR & $\mathrm{R}$ & NR \\
\hline & \multicolumn{14}{|c|}{ Londrina } \\
\hline $0-4$ & $6,9 \mathrm{Aa}$ & $6,7 \mathrm{Aa}$ & $6,9 \mathrm{Ba}$ & $8,5 \mathrm{Ca}$ & $13,9 \mathrm{Aa}$ & $13,3 \mathrm{Aa}$ & $3,2 \mathrm{Ba}$ & $4,4 \mathrm{Ba}$ & $1,3 \mathrm{Aa}$ & $1,4 \mathrm{Aa}$ & $5,6 \mathrm{Ba}$ & $6,4 \mathrm{Ca}$ & $2,3 \mathrm{Aa}$ & $2,9 \mathrm{Ba}$ \\
\hline $0-8$ & $7,1 \mathrm{Aa}$ & $6,7 \mathrm{Aa}$ & $10,6 \mathrm{Aa}$ & $11,9 \mathrm{Ba}$ & $11,6 \mathrm{ABa}$ & $10,3 \mathrm{Ba}$ & $4,6 \mathrm{ABb}$ & $6,2 \mathrm{Aa}$ & $1,7 \mathrm{Aa}$ & $1,4 \mathrm{Aa}$ & $8,4 \mathrm{Aa}$ & $9,1 \mathrm{Ba}$ & $3,8 \mathrm{Aa}$ & 4,1 Aa \\
\hline $0-20$ & $6,8 \mathrm{Aa}$ & $4,3 \mathrm{Bb}$ & $11,8 \mathrm{Ab}$ & $14,8 \mathrm{Aa}$ & $10,1 \mathrm{Ba}$ & $7,8 \mathrm{Ba}$ & $5,0 \mathrm{Aa}$ & $5,3 \mathrm{ABa}$ & $1,6 \mathrm{Aa}$ & $1,5 \mathrm{Aa}$ & $9,7 \mathrm{Ab}$ & $12,4 \mathrm{Aa}$ & $3,8 \mathrm{Aa}$ & $4,8 \mathrm{Aa}$ \\
\hline & \multicolumn{14}{|c|}{ Ponta Grossa } \\
\hline $0-4$ & $6,2 \mathrm{Aa}$ & $6,3 \mathrm{Ba}$ & $4,9 \mathrm{Ba}$ & $6,8 \mathrm{Ba}$ & $15,4 \mathrm{Aa}$ & $14,6 \mathrm{Aa}$ & $2,3 \mathrm{Ba}$ & $2,6 \mathrm{Ba}$ & $1,1 \mathrm{Aa}$ & $1,3 \mathrm{Ba}$ & $4,2 \mathrm{Bb}$ & $5,9 \mathrm{Aa}$ & $1,5 \mathrm{Aa}$ & 2,3Aa \\
\hline $0-8$ & $6,8 \mathrm{Aa}$ & 7,5Aa & 7,4Aa & $8,9 \mathrm{Aa}$ & $14,1 \mathrm{Aa}$ & $12,7 \mathrm{Ba}$ & $2,6 \mathrm{Ba}$ & $3,7 \mathrm{Ba}$ & $1,3 \mathrm{Ab}$ & $1,9 \mathrm{Aa}$ & $6,6 \mathrm{Aa}$ & 7,3Aa & $1,8 \mathrm{Ab}$ & $3,0 \mathrm{Aa}$ \\
\hline $0-20$ & $6,0 \mathrm{Aa}$ & $5,3 \mathrm{Ca}$ & $9,3 \mathrm{Aa}$ & $10,1 \mathrm{Aa}$ & $13,0 \mathrm{Ba}$ & $13,1 \mathrm{Aa}$ & $6,2 \mathrm{Aa}$ & $6,7 \mathrm{Aa}$ & $1,7 \mathrm{Ab}$ & $2,3 \mathrm{Aa}$ & $6,2 \mathrm{Aa}$ & $6,8 \mathrm{Aa}$ & $2,3 \mathrm{Aa}$ & $1,6 \mathrm{Ba}$ \\
\hline
\end{tabular}

${ }^{1}$ Médias seguidas da mesma letra, maiúscula na coluna e minúscula na linha, não diferem pelo teste de Tukey a $5 \%$ de probabilidade; os coeficientes de variação em relação ao número de plântulas emergidas, número de sementes recuperadas, número de sementes perdidas, número de sementes germinadas, número de plantas anormais, número de sementes mortas e número de sementes dormentes foram, respectivamente, 20,2, 17,6, 17,9, 22,9, 29,1, 21,4 e 35,5\% em Londrina e 10,8, 19,4, 8,3, 25,9, 28,8, 22,7 e 40,4\% em Ponta Grossa. 
didade de enterramento das sementes. Em solos revolvidos não houve efeito da profundidade de enterramento das sementes no número de plântulas emergidas em ambos os locais. Nas profundidades maiores, o número de sementes recuperadas foi maior, tanto em solos revolvidos como em não-revolvidos, nas duas localidades. Conseqüentemente, ocorreu o inverso em relação ao número de sementes perdidas.

A germinação das sementes recuperadas foi maior na maior profundidade de enterramento das sementes tanto no solo revolvido como no solo nãorevolvido, em ambos os locais. Não houve efeito de interação entre a profundidade de distribuição das sementes e o revolvimento ou não do solo sobre o número de plantas anormais em Londrina. Em Ponta Grossa, no tratamento sem revolvimento do solo, o número de plantas anormais foi maior com relação às sementes retiradas de profundidades maiores. Em Londrina, o número de sementes mortas aumentou com o aumento da profundidade tanto no solo revolvido como no solo não-revolvido. Em Ponta Grossa, o número de sementes mortas aumentou em profundidade somente em relação ao solo revolvido. Nas duas localidades, não houve efeito da profundidade no número de sementes dormentes no solo revolvido. Por outro lado, no solo não-revolvido de Londrina, o número de sementes dormentes foi menor na menor profundidade e, em Ponta Grossa, ocorreu o oposto, ou seja, o número de sementes dormentes foi menor na maior profundidade.

Esses resultados condizem com os obtidos por Yenish et al. (1992). Estes autores verificaram que em solos não-movimentados (ou plantio direto), a concentração de sementes é maior nas primeiras camadas; em solos movimentados (ou plantio convencional), a distribuição das sementes é uniforme nas diferentes camadas do solo.

\section{CONCLUSÕES}

1. Os maiores picos de emergência da B. plantaginea ocorrem no verão, coincidindo com as elevações de temperatura e precipitação.

2. Em solos revolvidos ocorrem maiores emergências dessa gramínea, do que em solos não-revolvidos.
3. As maiores emergências ocorrem nas profundidades menores de enterramento no solo.

4. Das sementes recuperadas do solo e submetidas a teste de germinação, os maiores valores de germinação ocorrem em sementes com um ano do que com dois anos de enterramento.

\section{REFERÊNCIAS}

BARRALIS, G.; CHADOEUF, F. Étude de la dynamique d'une communaute adventice. I. Evolution de la flore adventice au cours du cycle vegetatif d'une culture. Weed Research, Oxford, v.20, p.231-237, 1980.

DAWSON, J.H.; BURNS, V.F. Longevity of barnyard grass, green foxtail and yellow foxtail seeds in soil. Weed Science, Champaign, v.23, p.437-440, 1975.

DEBAEKE, P.; SEBILOTTE, M. Modélisation de l'évolution à long term de la flore adventice. I. Construction d'un modèle descriptif de l'évolution quantitative du stock de semences a l'horizon travaillé. Agronomie, Paris, v.8, n.5, p.393-403, 1988.

EGLEY, G.H.; CHANDLER, J.M. Germination and viability of weed seeds after 2,5 years in a 50 -year buried seed study. Weed Science, Champaign, v.26, p.230-239, 1978.

FERNANDEZ-QUINTANILLA, C. Studying the population dynamics of weeds. Weed Research, Oxford, v.28, n.6, p.443-447, 1988.

LEGUIZAMÓN, E.S. Seed survival and patterns of seedling emergence in Sorghum halepense (L.) Pers. Weed Research, Oxford, v.26, n.6, p.397-403, 1986.

POLLARD, F.; MOSS, S.R.; CUSSANS, G.W.; FROUDWILLIAMS, J.R. The influence of tillage on the weed flora in a succession of winter wheat crops on a clay loam soil and a silt loam soil. Weed Research, Oxford, v.22, p.129-136, 1982.

ROBERTS, H.A.; FEAST, P.M. Emergence and longevity of seeds of annual weeds in cultivated and undisturbed soil. Journal of Applied Ecology, Oxford, v.10, p.133-143, 1973.

ROBERTS, H.A.; FEAST, P.M. Fate of seeds of some annual weeds in different depths of cultivated and undisturbed soil. Weed Research, Oxford, v.12, p.316-324, 1972. 
ROBERTS, H.A.; RICKETTS, M.E. Quantitative relationship between the weed flora after cultivation and the seed population in the soil. Weed Research, Oxford, v.19, p.269-275, 1979.

SCHWERTZEL, P.J. The effect of depth of burial in soil on the survival of some common Rhodesian weed seeds. Rhodesia Agricultural Journal, Zimbabwe, v.73, n.4, p.97-99, 1976.

SCHWERTZEL, P.J.; THOMAS, P.E.L. Effects of cultivation frequency on the survival of seeds of six weeds commonly found in Zimbabwe, Rhodesia. Rhodesia Agricultural Journal, Causeway, v.76, p.195-199, 1979.

SHAFFER, D.E.; CHILCOTE, D.P. Factors influencing persistence and depletion in buried seed populations. II. The effects of soil temperature and moisture. Crop Science, Madison, v.10, p.342-345, 1970.
STOLLER, E.W.; WAX, L.M. Periodicity of germination and emergence of some annual weeds. Weed Science, Champaign, v.21, p.574-580, 1973.

THOMAS, P.E.L. Weed competition and reproduction studies in Rhodesia. Rhodesia Agricultural Journal, Causeway, v.74, p.21-24, 1977.

VOLL, E.; GAZZIERO, D.L.P.; KARAM, D. Dinâmica de populações de Brachiaria plantaginea (Link) Hitchc. sob manejos de solo e de herbicidas. 1. Sobrevivência. Pesquisa Agropecuária Brasileira, Brasília, v.30, n.12, p.1387-1396, dez. 1995.

WEST, S.H.; MAROUSKY, F. Mechanism of dormancy in pensacola Bahiagrass. Crop Science, Madison, v.29, p.787-791, 1989.

YENISH, J.P.; DOLL, J.D.; BUHLER, D.D. Effects of tillage on vertical distribution and viability of weed seed in soil. Weed Science, Champaign, v.40, n.3, p.429-433, 1992. 